\title{
Super Architects and dream factories
}

\section{Local and/or general}

The most recent and comprehensive study of architectural education in Australia, Papua New Guinea, and New Zealand was undertaken as part of an Australian Learning and Teaching grant awarded to Michael J. Ostwald and Anthony Williams in 2008. Ostwald and Williams had the difficult task of gathering up the spectrum of approaches to teaching architecture across all of Australasia and to analyse these for consistencies. Significantly, they report a special status for design studio, and in particular the nexus between graduating studio and the core competencies defined for architecture graduands within the terms of the AASA (Association of Architecture Schools of Australasia), plus the various local practice boards who manage the registration process for graduands to become registered practitioners.

One of the principal assumptions of the report was that studio remains the core syncretic subject in which the various parallel skills of architectural education came together and were expressed. In a report mindful of the broad range of activities of architectural education, the design studio was nevertheless afforded a special mention within the report recommendations:

The design studio is the focus of architecture programs in Australasia. The studio is where knowledge integration takes place; arguably an architect's most important ability. (Ostwald \& Williams 2008: 36)

In many respects, this is probably as it should be given the importance of consistencies in architectural practice which require a common pattern of organisational procedures, needs and behaviours. One expects architects to practise consistently within regional economic parameters, and one expects architectural educators and students similarly to approach education in a manner that is mindful of this reality. The studio then is the agreed model for emulating professional practice, particularly as a student matures through their programme of learning and becomes closer to graduating. In parallel, there are ambitions to address and teach more ambiguous qualities, such as 'creativity', however the nature and role of this value are less clearly understood, if universally desired.

Building on their 2008 study regarding architectural education, Askland, Ostwald 
and Williams (2011) posed a more developed set of questions in a later paper regarding the status and identity of creativity (149-156). Reviewing the same, or a very similar cohort of educators, it is clear that again studio is the location where 'creative' practice is understood to be exercised, and where students learn a variety of approaches. The problem-based learning model of studio work encourages forms of interaction between educators, students and amongst student peer groups that value and reward innovation:

Moreover, they illustrate a vision of creativity-and of teaching creative design-underpinned by a desire to expand students' creative potential by building their embodied understanding of creativity, their ability to think laterally and use their knowledge and skills to solve complex problems. (2011: 156)

None of this conflicts with any generalised discourse on the nature of architectural education when viewed through the lens of pedagogical mission statements and the like. Yet the broad nature of the analysis omits any detail capable of distinguishing what might be problematic in the conduct of design studio, particularly that of graduating students. What then do we make of the many graduating projects that seem to have become more visibly exotic, relative to the highly managed programme of competency and compliance called for by professional life? Further, what is being pursued in these projects that makes them so deliberately and fictionally disengaged from our current reality and which evoke states of affairs far beyond everyday experience?

This paper will consider precisely these questions. It will, firstly, interrogate graduating project work as processes of world-building that reveal themselves to be complex meditations on possible worlds and philosophical states. Secondly, it will attempt to categorise the indicative approaches found in these exercises of world-building. The reasons for approaching these issues in such a way is as much methodological as it is respectful of the indissoluble idiosyncrasies of the work presented. The aim overall is to find in these idiosyncrasies underlying tendencies that might contribute to a framework for attending to them more critically.

Take for example Sunny Qin's narcotic and delirious "Paradise of Paradises" project (Qin, 2014; see Fig. 1), or his equally marvellous "City of Mainkon” (Qin, 2014; see Fig. 2), which demonstrates the presence of an idea-that paradise is a material reality and the result of a collective wish fulfilment in a "post scarcity and post singular" universe (2014). Whatever the fine-grained analysis of the rationale behind the project, gained through scrutinising the febrile relationship between the text and image animating the work, it is clear that Mr Qin's ambition for the projects is not to illustrate the forms of competence that pass for a job-ready graduate architect. And while he may now be interested in the conventional process of design and manufacturing resultant in built work, we know that, as a student, his preoccupation was with evoking an image of a place, or a state, that contained some recognisable threads of the literature of paradisiacal environments.

However, perhaps the most pertinent of the initial questions that might be asked are, why are projects such as this attempted within architecture schools? Do they represent the persistence of traditions preceding a modernist concern with social immediacy and material technologies? Historically, there has been a consistent 
tension between the pragmatic and the fantastic in the conduct of student architecture projects since the establishment of the French Beaux Arts system of the $17^{\text {th }}$ century. Peter Collins (1966) however notes that, by the 1960s, a trenchant criticism of the form of florid speculation that these schemes demonstrated ultimately led to the abandonment of the Grand Prix de Rome, the signature award for creativity within the academy.. This criticism seemed to validate many of the discussions regarding the politicisation of the effects of architecture, most powerfully in comparisons between work by students at the AA and those of the Unité Pédagogique No. 6 in the late 60s (see for instance, Pawley and Tschumi, 1971: 336-366).

Despite being separated by fifty years, this moment in history should seem familiar since the debate within architecture schools regarding the character and direction of graduating projects has not really changed significantly. It demonstrates the classic structuralist trope of form and content within a dyadic argument in which changes in form occur. While the difference between Kahane's 1966 effort and Qin's 2015 piece are clear, the content remains consistent inasmuch as they both occupied an experimental relationship to orthodox practice.

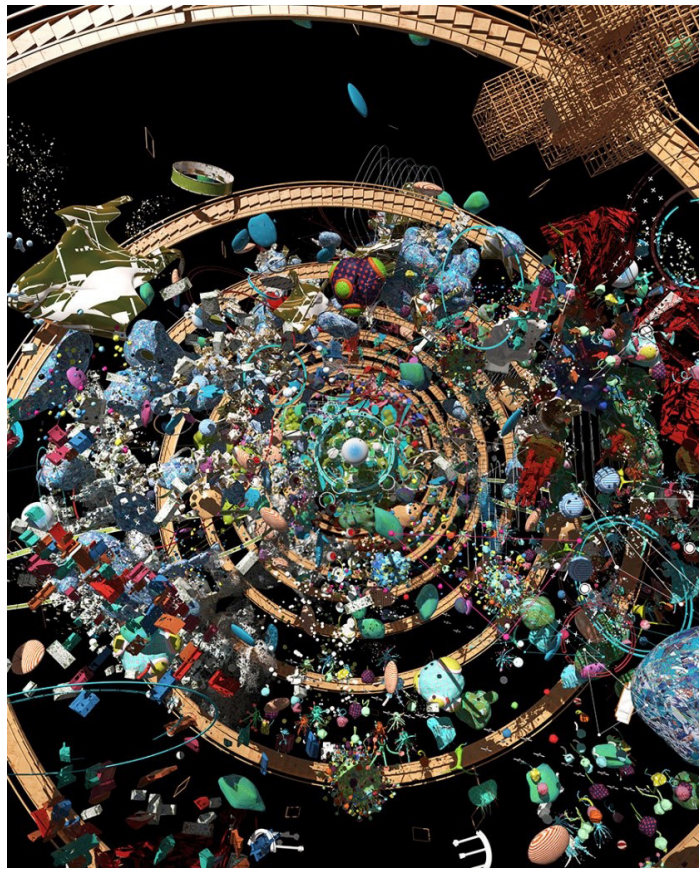

Fig. 1 Sunny Qin (2014). "Paradise of Paradises: The Library of Paradises" [Render, Super Architects]

Fig. 2 Sunny Qin (2014). "City of Mainkon” [Render, Super Architects]

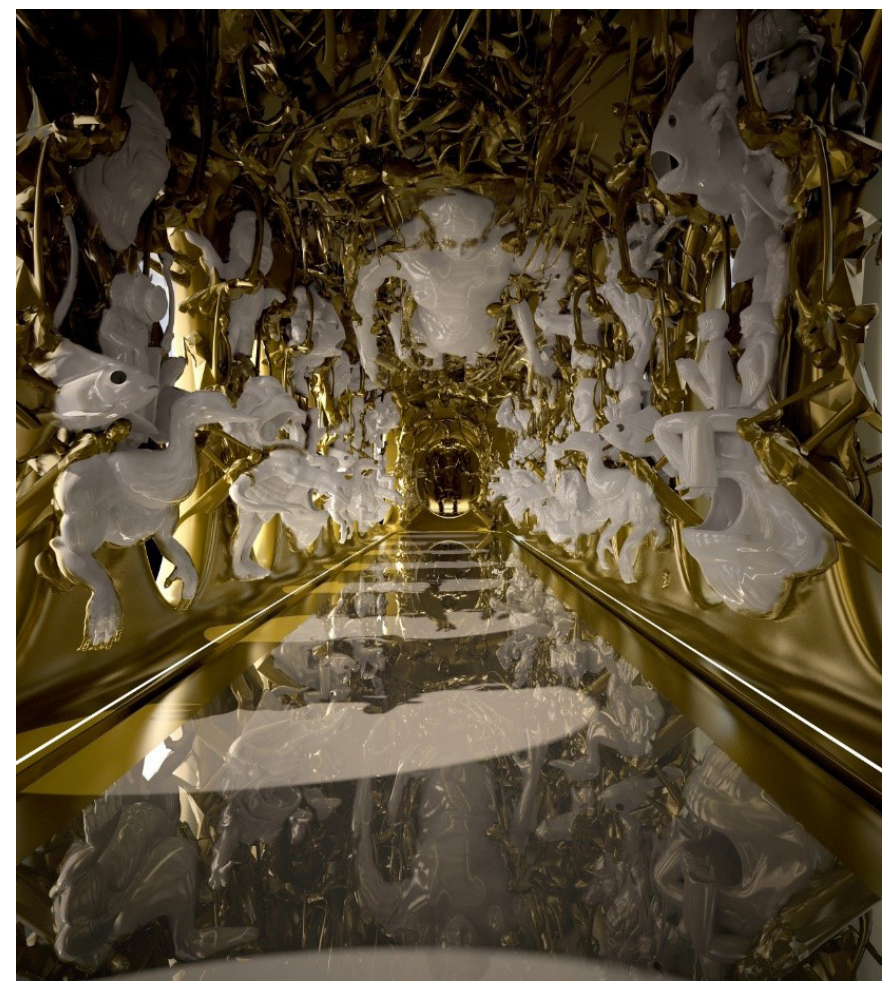




\section{Original showing: Super Architects}
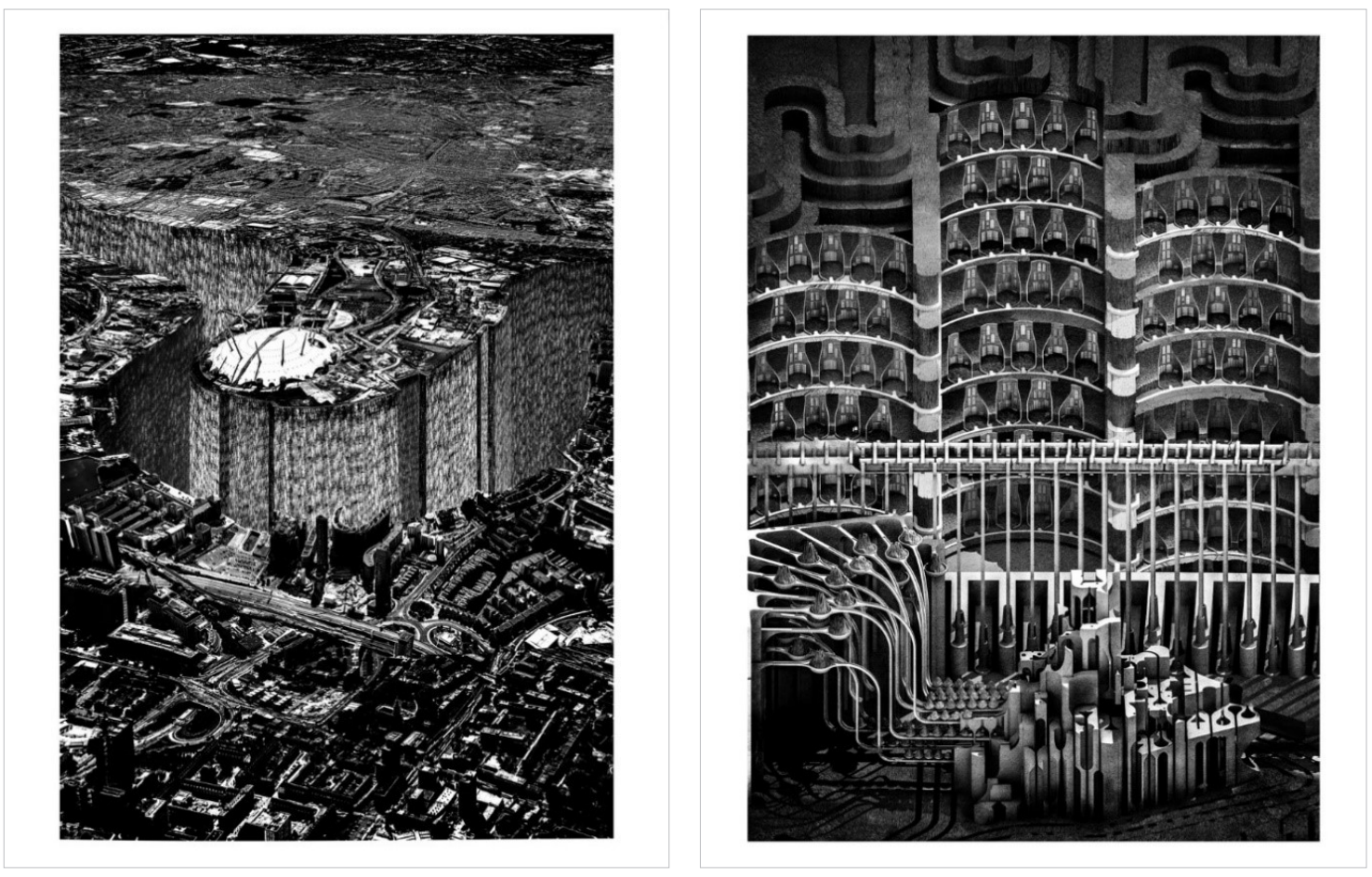

Fig. 3 \& 4 Pamela Toh (2015). "Soil City” [Render, Super Architects]
The evolution of experimental student work has only recently attained a broader visibility beyond that afforded by the curated forms of publications associated with architectural schools, for example, in the United Kingdom via the Bartlett and the Architectural Association, and within the United States, via the Harvard Graduate School of Design or SciArc. This is not to say that such work has not been produced outside of these institutions, or been the product of intense effort in other quarters-but the visibility of this material has been an issue. In many respects this appears to be the consequence of two parallel conditions of the work: its sheer abundance; and its status as a form of juvenilia. The briefest survey of the work captured in the Bartlett annual review, for example, reveals an abundance of thematised approaches. Bartlett 2015 documents 28 different studios with a wide variety of subjects of study. This diversity exponentially increases when the number of student projects per studio is considered.

Similarly, it is assumed that the work constitutes a form of juvenilia that disqualifies it from serious consideration. If the work is not directed to possible solutions that have immediate efficacy in 'real-world' circumstances, their principal role is as a rhetorical demonstration (progymnasmata) of intellectual agility and communicative sophistication (Fleming, 2003: 105-120). Studio then is an exercise much like the rhetorical exercises of antiquity where student work only occurs, and has any relevance in, the artificial world of education.

Finally, there are tangible differences of academic credibility between the work produced at the level of graduate students and the established genre of visionary fabula that stems from mature practitioners. This lineage extends from the illustrations of the Hypnerotomachia, through Piranesi, Sant'Elia and Chernikov to more recent work by Lebbeus Woods, John Hejduk, early Daniel Libeskind, and 
Zaha Hadid, to name a few. This work, arguably because of the legitimating process of scholarly study, is generally considered to have demonstrated theoretical complexity specific to their historical moment. Further, if we think of less famous practitioners such as Ben Nicholson and Lars Spuybroek, for example, the value of the innovatory aspects of their work seem to be tied to their (arguably lower-tier) status within the intellectual economy of the academy (see Nicholson, 1990, Spuybroek, 2004). Following this arc, the work of students and graduates, because it is unknown, may be presumed to be derivative of the world-view of more established theoretical expressions, and consequently of lesser academic credibility.

But is it? Much undergraduate and graduate work is symptomatic of dominant contemporary discourses on the role and value of the historical and contemporary avant-garde. What is unquestionable is the abundance of material produced at this level and the vast heterogeneity of 'worlds' they attempt to invoke.

This is potentially where the work submitted and published by the website Super Architects can be thought significant and worthy of consideration. The site brings together student and recent graduate work that fits into a tradition that seems to revive the idea of the "grande rhetorique". However, it does so through the organic process of user submissions and the circumstantial interests of the editorial board. The website, according to its own mission statement, is an anonymous collective of interested parties that support the cultivation of the new. They say:

$\mathrm{S} / / \mathrm{A}$ is an unprecedented democratizing force that's willing to revitalize and provide a platform for architectures' emerging counterculture; therefore a network for a new breed of thinkers/doers, who continue to render alternative, unconventional, and experimental ways of reconstructing what architecture might mean in/for the future... (http://superarchitects.world/ pages/about/)

The schemes do not demonstrate an even level of invention, which is understandable given the relatively moderate and inclusive level of editorial curation. Some schemes demonstrate a level of competence and thematic focus that is consistent with professional practice and could, conceivably be built without too much of a challenge to contemporary interests. Some, however, demonstrate a degree of invention and intention that challenges the values outlined above with respect to the profile of creativity within the design studio in the Australasian reports. The great value of the site, and ones like it, is that its content comes without an overt curatorial bias in the first instance, or a concerted public identity that is managed to create consistency, or to demonstrate specific success of an educational program. Its life is dependent upon the efforts of the community that uploads material for publication.

The manifesto itself is suitably generic to cover the general aim of supporting an emergent movement of architecture graduates sharing an interest in pictorial and thematic richness. This has, as we shall see, allowed the editorial collective to commit to a particular philosophy of the rhetorically fantastic. So, for this reason, a closer understanding of what the open concept of "alternative, unconventional and experimental” actually denotes will be pursued in a more fine-grained analysis below. 


\section{Theories on the impossible}

At a first level of analysis, it warrants asking to what extent do these works, with their world-building propensity and will to view the given differently, draw on and contribute to, or extend, a broader tradition in architecture concerned with the utopian. An examination of utopian impulses in European architecture from the seventeenth century has been undertaken by Manfredo Tafuri $(1976,1987)$ in his highly refined Marxist review of the relationship between cultural production and Capital. Tafuri's studies on Piranesi and avant-garde modernist practice specifically, and on utopian thinking in general, dominates the intellectual field in these forms of architectural analysis.

But the question should also be-does the model of a totalising vision apply anymore in the ongoing issue of 'what to do'? Tafuri, and the debates on post-modernism, predated the changes in cultural practice arising with forms of economic consciousness linked to the sustainability movement, and also the impact and opportunities of proliferating engagement arising with digital culture. Utopian theory then, if it is appropriate to characterise the emergent student work as being 'utopian', seems to have emerged after the interregnum of post-theory discussion on the exhaustion of totalizing narratives of architectural meaning and purpose (see Frichot, 2009). What does provide a bridge between these historical moments-the cultural Marxism of the 1980s and 90s, and the contemporary plethora of visionary material-is Fredric Jameson's analysis of utopia in Archaeologies of the Future (2005). Jameson's own engagement with Tafuri, and the question of utopian architectural production, is complex since Tafuri's insistence that all form is tied to the totalizing and reifying aspects of capitalism results in the pessimistic conclusion that architecture has no role other than to confirm the presence of power and unequal social relations (see Day, 2012). Jameson concentrates upon the literary tradition of science fiction in Archaeologies of the Future, but the understanding of architecture's role as utopian, filtered through Tafuri and cementing the plausibility of the utopian imagination, is a core concern of his.

Jameson differs from Tafuri insofar as he does not concentrate on the pessimistic instrumental relationship between architecture and dystopic futures as a project. Within Archaeologies of the Future, architecture is present as a fundamental condition within the utopian condition, but is not discussed as a problem to be solved. For example, when he investigates a specific condition, such as Charles Fourier's utopian thinking, he does not consider it appropriate to extend his analysis of architectural production past Tafuri to a specific example such as the phalanstère. He does however suggest that 'structure', in the sense of structuralist anthropologies and their material, is a core aspect of utopian thinking (2005: 228). But, as Gail Day has noted, the mode of theoretical analysis within architecture that follows the scholarship of Tafuri and Jameson remains committed to the idea that utopian thinking is overtly a demonstration of resistance and emergence, not progress. She argues:

Tafuri represented a "critical refusal of utopian speculation", which seemed to threaten the progressive purpose that Jameson especially attributed to utopian thought (and which still remains central to his intellectual endeavour). (2012: 60)

So if Tafuri and Jameson do not wish to propose architectural 'structures' that 
might support or encourage changes in social inequities in the broadest sense, Jameson does still see seriousness in the literature of the imagination in science fiction. The benefit of studying Jameson's engagement with utopian thinking is that it gives considerable intellectual credibility to the thematic and intellectual consistency within the speculative ontology of this literature, a condition that ultimately has specific relevance to a component of the Super Architects material considered here. The question is whether the world-making and temporal displacements, if not out and out futurism in the student and graduate work, is something other than a melancholy rehearsal of the impotence of architecture to design a utopian future, or if it may have other, unarticulated values and motivations at work? The points below are intended to provide some indication of where this discussion might head. They are intended to capture some of the principal themes that seem to be consistently present in current speculative architectural work, and to give some indication of the categorical co-dependency of ideas that are opened in Jameson's approach to science fiction literature, except with a focus on the world-view (Weltanschauung) of critical architectural practice.

Fig. 5-8 Samee Sultani (2014). "Mute Peregrinations Through a Narrow Conduit" [Renders, Super Architects]
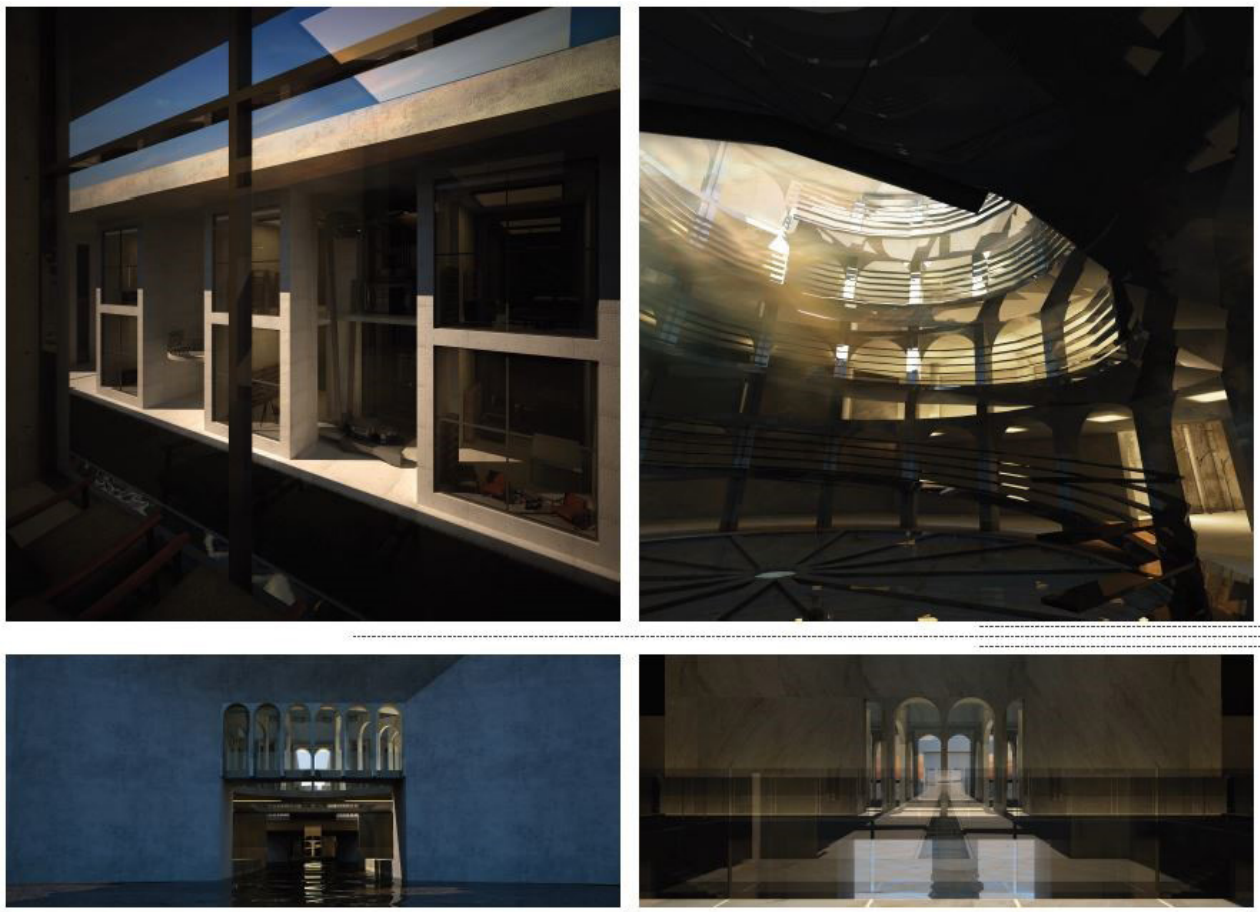

\section{Some notes on approaches}

Looking across the breadth of the schemes listed on Super Architects, some thematic issues emerge that are worth isolating. In the main they demonstrate issues that involve questions of counter-factuality and historical materiality, of technology and its instrumentalities, and, of possible ontologies and the organic limits of the human body. The schemes involve some form of impossibility at a general level, or are idiosyncratically self-reflexive to the point of hermeticism or monomania. Nevertheless, it is possible to develop a few characteristics that apply to much of the work. 


\section{Counterfactuality}

1. Projects are not recognisably and immediately feasible in that they infer an impossibility/or some lacunae of plausibility.

The schemes generally incorporate conditions that depart from the everyday by framing questions that are different from issues pertaining to commonplace, typological familiarity (a school, an office building etc.)-for instance, Sunny Qin's work concentrates on the aggregation of ideas of paradise, Samee Sultani's proposal (Figs. 5-8) is for a museum of ambiguity in Sydney, and Pamela Toh's project (Figs. 3-4) looks at the storage and management of topsoil in urban London. All of the schemes rely on an initial premise that ultimately inflects the decision-making process for proposing material and economic conditions that will be shown to be ultimately plausible in the scheme. The schemes are therefore tasked with making the strange or impossible present and legible. To do this, they must create a world condition or state of affairs that draws on some understanding of what may have been historically present, but which has changed for reasons that are sometimes explicit. This counterfactual condition then supports the emergence of a premise based upon impossibility and implausibility.

Counterfactuality and the possibility of parallel fictional narratives that employ aspects of the 'real', transformed by possible alternate 'states of affairs', is the substance of modal logic in philosophy explored for example by Saul Kripke (1972) and David Lewis (1973), and in studies of fictionality by Lubomir Doležel (2000). The particular nature of counterfactual thinking in modal philosophy is to speculate on the logical possibility of an event for which there is no material evidence of its occurring. For example, the idea that Germany and Japan won the Second World War is not materially true, but is logically sensible. What then happens when the logical consistency of this problem is generally not the concern of the philosopher, but is of intuitive interest to persons interested in theories of fictionality? In theories of narratology, the core question arises-how do we suspend belief and believe in something we know not to be true? This proposition is pivotal in theories of fictionality, possible worlds, narrative theory, meta-narration and meta-fiction (Hühn et. al., 2016). The work curated within Super Architects, it can be argued, amply and comfortably demonstrate an engagement with these same theoretical questions.

2. An historical material condition is implied, inasmuch as a project presents a state of affairs 'in medias res'.

The term in medias res denotes a literary convention in which a narrative commences in the middle of the events it depicts. The narrative is usually in the present tense and without an elaborate construction of historical developments that have led up to this point. In terms of the temporal experience of the work, there is an emphasis usually on the viewer simultaneously discovering the project, as a reader might discover the major aspects of a narrative, or of a traveller being introduced to an exotic location in a travel description. Within an architectural scheme, the reality of its conditions is made immediately apparent because the images produced present a totality that is already real. The viewer is immediately placed in the temporal and spatial reality that the project frames and, as part of the narrative that the project controls, the complexities of the project are unfolded as it explains the world conditions it proposes. 
This condition is acutely important in recognising the level of (dis)engagement of the work from theories of the future that typified questions of theory in the examples above concerning Tafuri and Jameson. Temporality is not the function of historical forces alone; it is also the reified and most palpable moment of 'now'. Taking the issue of counterfactuality in point 1 above, it could be one of several temporally immediate conditions (or 'nows'), but it is clearly one in which we expect the performance of the project to take place. In this respect, the 'nowness' of the projects is its synchronic and diachronic profile, suspended at the moment the author-architect believes it is most powerfully communicating its qualities and intentions. What circumstances are assumed to have led to this point, and what will transpire, is captured in the chains of causation the project implies.

3. The state of affairs involves a series of counterfactual propositions about agency and effect.

The world-making associated with the state of affairs induces causal chains within the work. Often the project description will summarise a series of catalysing conditions that have led to the circumstances of the project, but there are also implicit agencies and effects in the work that can be recognised. In Pamela Toh's work (Figs. 3-4), this is a series of environmental events that have initiated a crisis in food production and management. In others there are conditions of political instability or economic relations that can be identified. Causation then is an important transitive condition within the work, as it addresses the dynamic environment that the project exists within. Sometimes these effects are the product of human endeavour enhanced or situated within the project's architecture, or sometimes they are the outcome of instrumental technologies that the project initiates or supervenes.

Often the issue of causation is related to questions of scientific processes that are relevant to architectural practice. Whether it be a condition of environmental crisis in which various peak conditions have overtly occurred such as exhaustion of resources, or one in which potential energy resources or information and data management can be organised for more enlightened ends, the projects define ways in which this might come about. Generally, as a consequence of the point above, the exact explanation of how the science of this condition occurs is only lightly explained, if at all. The operative condition is one that just exists as a paradigm to be confronted or worked with, rather than explained. Architectural practice is therefore caught up in this confrontation.

Dominic Dickens' “Dead Drop City”, (Fig. 9) a community of crypto-anarchists, behave in ways that are highly orchestrated. As he says:

The secretive society live and work on their purpose built [sic] site in East Greenwich, manufacturing a range of goods through a series of cottage industries. The products manufactured range from the Dead Drop City Manifesto in the printing press, radical crypto-anarchist propaganda, and 'digital bricks' or the building blocks for a new city which contain data information storage on which the Dead Drop City Manifesto is loaded and can be accessed by passers-by. Raw materials are mined on site to allow the city to operate and produce these goods independently. (Dickens, 2014)

The programme of actions and their effects are identified through Dickens' design process. At times he presents the city's functioning as a hegemony, 
Fig. 9 Dominic Dickens (2015). "Dead Drop City" [Render, Super Architects] immutable in its processes. At other times the project imagines the catalysing effects of the architect/viewer as a presence that inflects these processes.

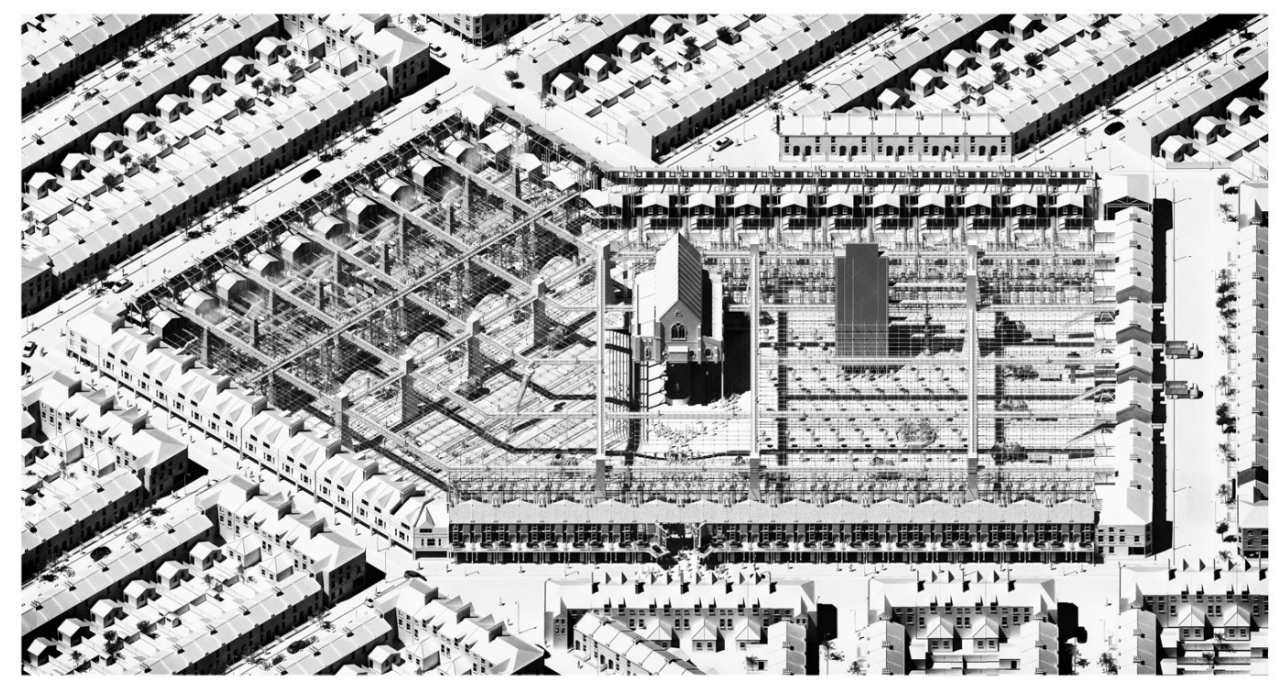

\section{Technology}

4. The ontology of the project suggests forms of existence in which maximally (dis)advantageous choices are being made, or need to be made.

In the first instance, most of the projects that exhibit the aspects that we have already outlined also often require that their users or inhabitants follow certain types of practices. As a core aspect of the imagined circumstances in which these projects can occur, there is a concomitant pressure on the users to behave in ways that confirm the dominant effects of the architectural project. Thus, like Foucault's identification of the disciplinary cultivation of 'life', demonstrated in his studies of prisons, hospitals and other discursive structures, forms of life are mooted to develop as a consequence of material conditions (architecture's disciplinary function) that condition the evolutionary development of an organism (see Hirst, 1993: 52-60). Conversely, emancipatory architectural projects can be analysed for their properties as discursive formations of types of liberating behavioural, and thus epistemological, practice. While all architecture demonstrates a degree of this condition, conceptual projects deliberately exacerbate and exaggerate this as a condition of their effect. One of the conditions for existence within the projects is that it demands behavioural disciplines that are different from conventional norms. Whether it is the crypto-anarchists of Dickens' project, or those of more anonymous users, projects assume and compel users to fulfil the project's implicit behavioural instrumentality.

In this respect, a number of the works within Super Architects sit beyond Tafuri's pessimism precisely because the existential conditions they imply are ontologically distinct from the historical material conditions he critiques. Much like the pharmacological experiments of Alice in Wonderland, the limiting case is the tolerance of the body to withstand an alternative version of the self. Architecture then is the material means by which the undertaking of these maximally enhanced and altered ontological states are made recognisable. 
Fig. 10 \& 11 Lewis Armstrong (2015). "The Thermoelectric City" [Renders, Super Architects]
5. The economic circumstances of the states of affair are tacitly presented, if not fully demonstrated.

In most projects there is evidence, however peripheral, of the presence of a supposed economy. The assumption that there are exchanges of goods and services that affect the functioning of the project is a common trait. In many respects, the way in which the project works act as a proposition within an economic mode of production that defines its overall mode of functioning. This is particularly so with projects in which the prosthetic relationship between human form and technological 'function' implies both an instrumental outcome of the supposed technology and a volitional choice of the presumed inhabitants.

In the absence of specifically novel economic mechanisms being proposed, projects found in Super Architects sometimes suppose economic collapse or lapses in previous economic organisations. Echoing Walter Benjamin's melancholy consideration of nineteenth-century Paris, technology is made the means to overcome a problematic instrumentality itself associated with technology (see Buck-Morrs, 1991 \& Gilloch, 2013). Consistent with Benjamin's studies, the examples within Super Architects demonstrate a phantasmagoria of utopian modernity as both the acknowledgment of the failure of the present and the explicit desire for its overcoming. Lewis Armstrong's "Thermoelectric City", (Figs. 1011) for example, is premised on a conflation of economic necessity and sublime reverie, in much the same way that Antonio Sant'Elia imagined his Città Nuova project of 1914.
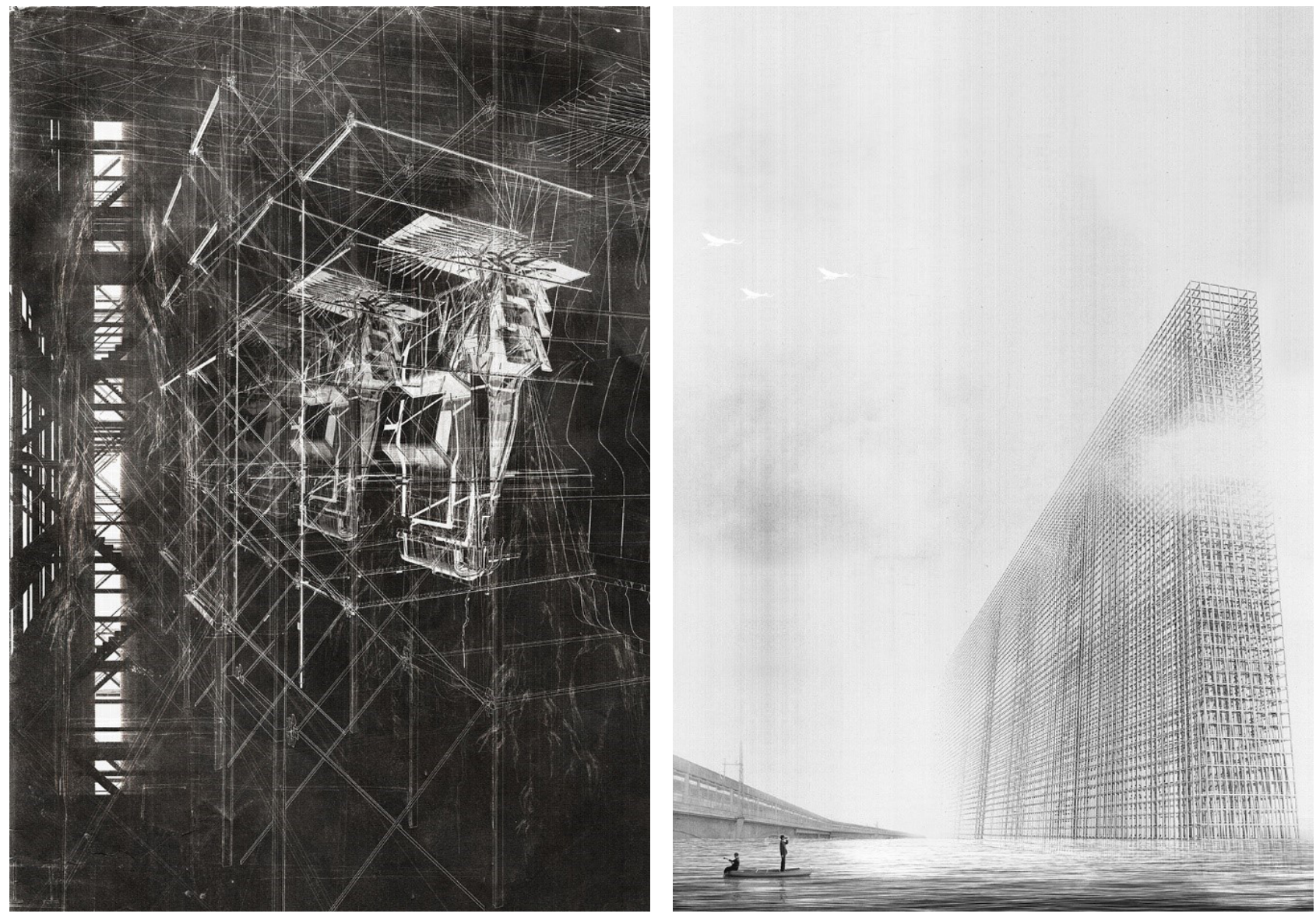
Jameson speaks of this economic moment, the design and production of an urban-scape of the imaginary, when discussing Tafuri's and Cacciari's analyses on the impulses of modern urban planning:

It is also useful to turn this rather different meditation on temporality [...]-that of Tafuri and Cacciari, who see this neutralized future as a form of insurance and of planning and investment, a new kind of actuarial colonization of the unknown. It is thus not merely to deprive the future of its explosiveness that is wanted, but also to annex the future as a new area for investment and for colonization by capitalism. Where Benjamin observed that "not even the past will be safe" from the conquerors, we may now add that the future is not safe either. (2005: 228)

Here the colonisation of capitalism described by Jameson, devolves in certain projects into micro-economies that exist only as half-lives of an idea. Each project gathered in Super Architects proposes and plays out an 'economy' of cause and effect. Yet they are no more, or less, serious than the revolutionary project of socialisation imagined by co-operative society. Within the discourse of what constitutes a 'serious' question for architectural imagining, the economics of the Super Architects work is perversely uneconomical because of its commitment to the 'un-safe' effects of the sublime. For example, Armstrong's "Thermoelectric City" (2015) proposes a gargantuan technological and economic structure, the raison d'etre of which is simultaneously to overwhelm the viewer while promising the liberative effects of systematised technological production.

\section{Projects valorise technological fixes to existential questions.}

This is one of the more explicit and overt conditions within speculative projects, particularly those concerned with environmental conditions that seem to require interventionist solutions. Employing forms of analysis and communication that are common to architectural research-diagrams, data maps, cause and effect fields - these propositions valorise technological solutions. Often this involves

Fig. 12 Daphnie Costi (2014). "Tubascular" [Render, Super Architects] suppressing aspects of the other conditions identified here, such as scientific probity, credible economic modelling and social behaviourism, in order to explore the potential technological outcome.

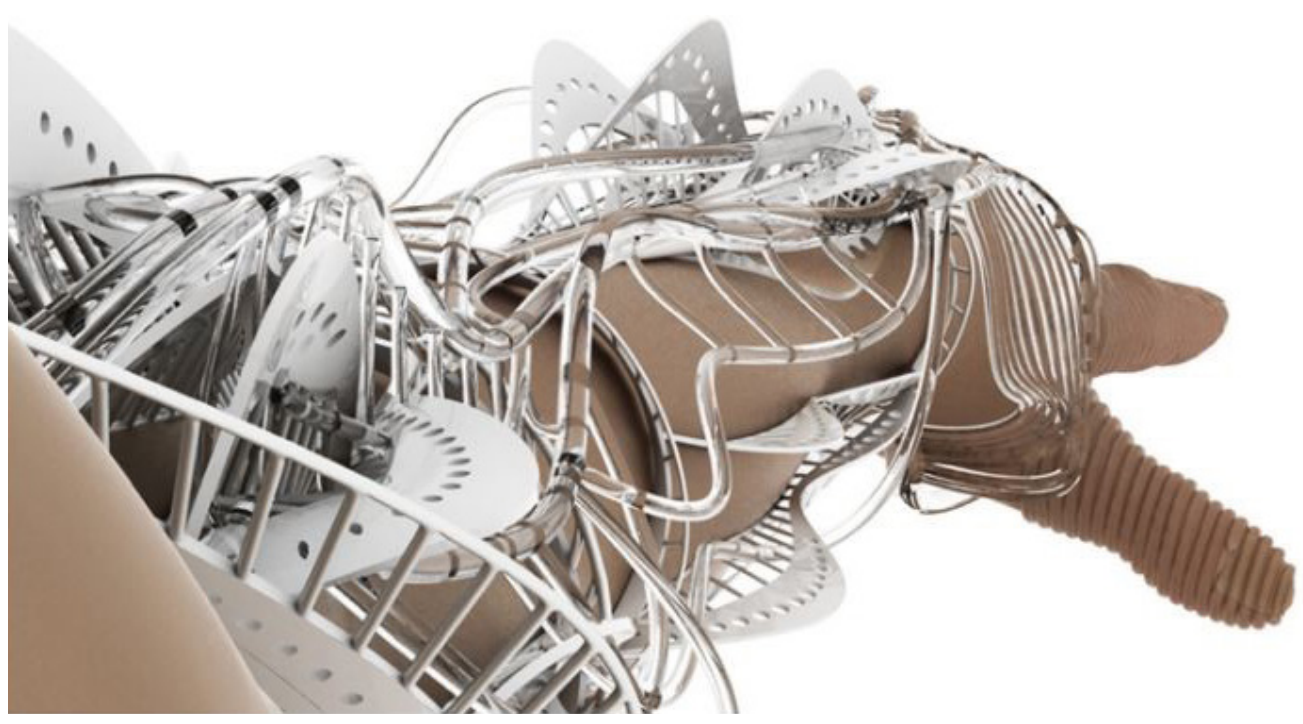


Often, considering these propositions objectively, the technological conditions are closer to propositions that mythologise its relationship to the human condition. Martin Heidegger's "Question Concerning Technology" (1977), though rarely cited, succinctly frames the qualia of this position. As Heidegger notes, technology is a bringing-forth of humanity's instrumental relationships and foregrounds the metaphysical implications of this condition rather than the logistics of power generation and management. At a more intimate level, and consistent with the scope of technology generally imagined and visualized by Super Architects projects, is the deployment of tools, particularly in the sense of Heidegger's encomium on 'tool-being' (Zuhandenheit). Architecture is a complex gathering of tools, and is a collective tool itself, that works on the world. The status of tools as purposive 'objects' that interact with the world, changing its material conditions while recognising the object-oriented nature of such an interaction, remains an important but rarely stated characteristic of the most speculative architectural projects (Harman, 2002). While directed at an aestheticisation of a mechanical prosthetic, Daphne Costi's “Tubascular" project (Fig. 12) is arguably more about the ambiguous status of the self as both "tool being" and as object (Costi, 2014). In this sense, projects engaging with technology tend to do so by deploying tools to construct worlds. While any of the Frankenstein fables of human/technology interaction rehearse the pleasure and horror of this encounter, the clear premise is that architecture is the outcome of this process of ontological construction (Gandy, 2010).

\section{Ontologies}

7. The organic limits of the body and its prosthetic augmentation are questioned.

In almost all projects there is the assumption that the worlds created are nominally inhabitable. Even Sunny Qin's seemingly impossible to occupy world bears human connection. Despite his paradisiacal world existing outside of conventional spatial and temporal limits, it nevertheless retains traces of the dreamscape and reverie-human reveries-that initiated it. Further, the work is dependent on our engagement with it as a proposition. Not only does its intelligibility rely on Mr Qin's depiction of it, but its functioning rests on a questioning of the philosophical trope embedded in it.

More generally, the relationship between architecture and human scale is a commonplace of architectural theory. From issues of proportional concinnitas, to those that hypostatize prosthetic technology at an architectural scale, there seems to be a clear motivation in many Super Architects projects to bring into measure the differences between organic and inorganic conditions, as suggested above. Furthermore, the design approach that utilises organic processes to 'grow' built structure, as a host for human activity, also explores the limits of biological and technological understandings of sentience. Natalie Alima's "The Bio Scaffold" (Fig. 13) proposes a complex structural paradigm that is grown rather than constructed and Costi's “Tubascular” project (Fig. 12), as we saw, explicitly proposed an architecture of the body that supports and weaponises the human-machine relationship (Alima, 2015; Costi, 2014). 
Fig. 13 Natalie Alima (2014). “The Bio Scaffold” [Render, Super Architects]

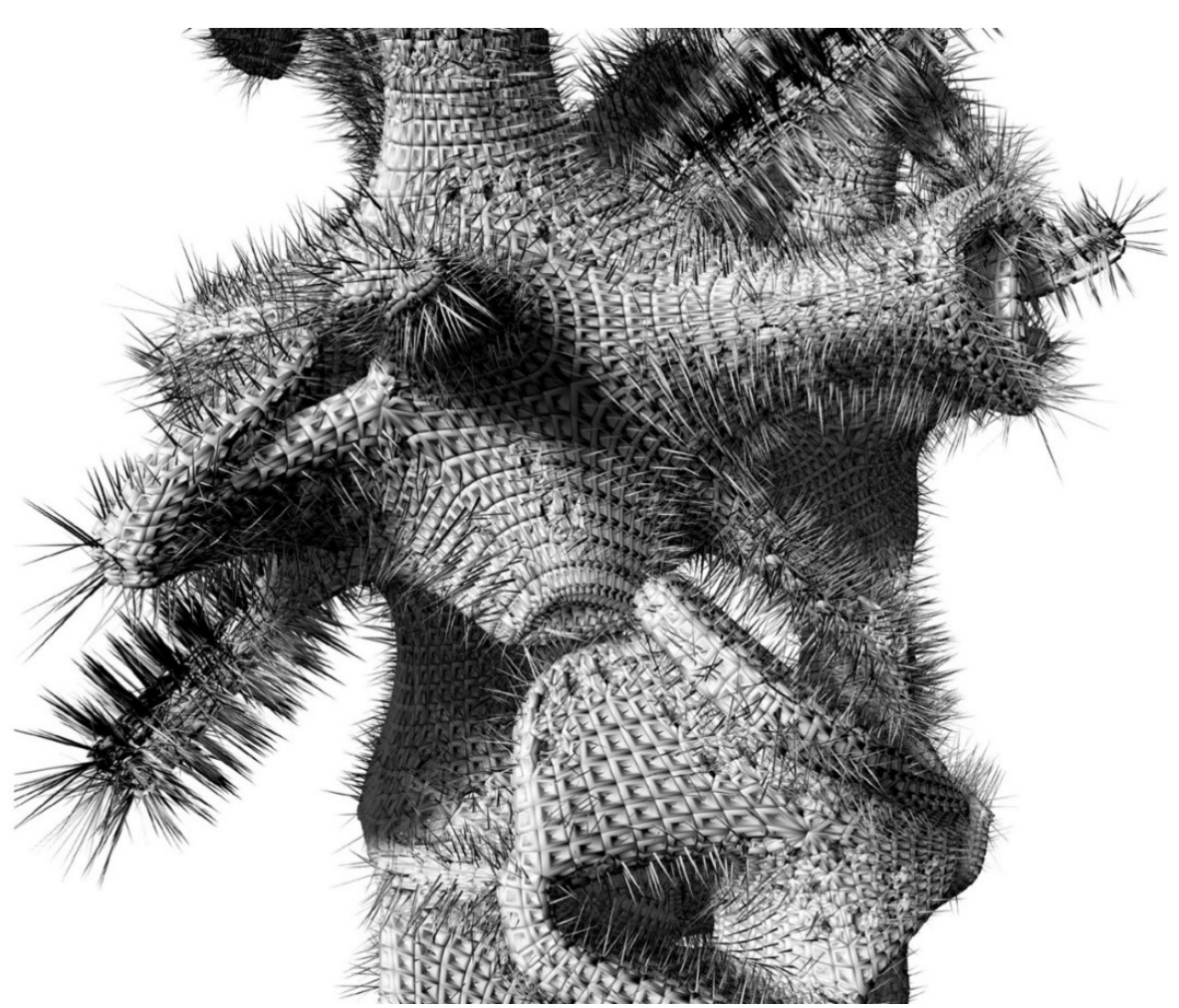

8. Behavioural and psychiatric pathologies may motivate the projects, but these are amplified beyond the personal. They are taken as both collectively relevant and politically significant.

Given points 4 and 7 above, it is evident that many projects mobilise compulsive and obsessional factors to disrupt conventional programmatics and to instil in them alternate worlds of unconventional, if imaginable, behaviour. Concomitant with this strategy is a broader questioning of behaviour, free choice, and freewill, themselves inseparable from the issue of ethical choices. This is politics at its most visceral and, when combined with propositions that involve transformations of economic relations, it is clear that there are many political questions to be answered in many of these projects, though their authors rarely address these issues explicitly. Perhaps if they did, many of the projects would never reach completion.

Obsession and repetition, while typically indicative of pejorative psychological conditions when taken as a premise for an architectural project, work to counter normative expectations of balanced responsibility in projects. Yet, as Andrew Benjamin argues, repetitious return is the very essence of memory and its mobilisation - a mobilisation that is itself central to architecture and its critical dimensions:

At its most minimal, however, the implicit work of memory is the work of repetition. Repetition inscribes. What this means is that it is only in terms of repetition that an account can be given for how and in what way any new project is architecture's work. The doubling of repetition occurs because not only does repetition announce the possibility of a continual reiteration of the given, there also has to be an allowance for a form of repetition in which architecture can sustain a specific critical dimension. (2000: 43-44) 
Along these lines, the promotion of obsessive behavioural expectations within architectural projects can be seen as a form of communicative 'bracketing' that bring forward the philosophical purpose of the project. Like the insistent presence of certain behaviours in the sketches of Le Corbusier-looking, reclining, exercising, being-absent-the work presents its argument most clearly through repetition.

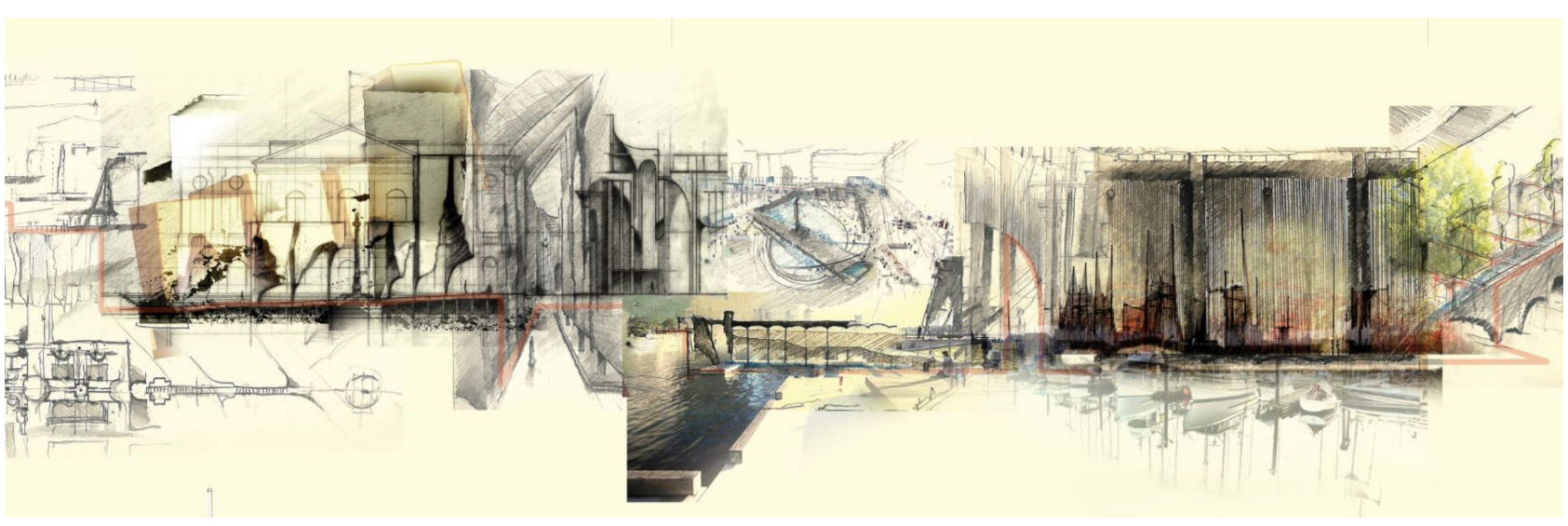

Fig. 14 Ed Meyers (2014). Lisbon Market Project [Render, Super Architects]
9. The projects aim for poetic value and quality as one way of overcoming a melancholic finitude in things.

Finally, many projects strive for poetic beauty. The renders they exhibit are characteristically rich and complex. While depicting their intended proposition with much seriousness, the projects nevertheless maintain the pictorial dimension as itself a critical and necessary aspect of the architecture.

And yet, the projects also represent conditions, if viewed generously, in which the positive aspects of the work, politically speaking, can be focussed on. The emancipative opportunities of complex aesthetic experience-Theodor Adorno identifies this as "truth-content" (Wahrheitsgehalt)-can reveal both critical problems within social formations and possible moments of transformation of consciousness. The virtuality of this experience, its immanence as a counterfactual possibility, makes its political value clear. Aesthetic complexity is what makes the comparative and critical dimension of the projects possible by the very imaginative weight of their architecture.

\section{Conclusion}

While the points above can only briefly characterise and question the tendencies evident in contemporary design practice within current architecture schools, they hopefully point to a gap that currently exists in the critical space within which they are evaluated. Though there are clearly locations that support these works through the development of clear critical practices, it is also the case that this is a fragmentary and individualised condition dependent on specific school cultures. What is certainly clear is that there is little literature that gathers these tendencies together and speaks across disciplines to the practice of exploratory design at this level, the level that the editors of Super Architects have recognised contains material of significant public interest. 
Often the issue of what maturely constitutes the avant-garde is directed towards practitioners, or towards architect academics who have sufficient scholarship to situate their own work within the type of conversations framed by institutions such as the Graham Foundation, the Venice Biennale, or the Architectural Association, to name a few. But if we think of the process of origins as one of complexity promised but not yet realised, then the body of work that Super Architects captures is itself a form of origin myth, if carefully understood. 


\section{REFERENCES}

Alima, N. (2015). The bio scaffold. Retrieved from http:// superarchitects.world/portfolio/ bio-scaffold/

Architectural Association projects review (2016). Retrieved from http://pr2016.aaschool. ac.uk/

Armstrong, L. (2015). The thermoelectric city. Retrieved from http://superarchitects.world/ portfolio/the-thermoelectric-city/

Askland, H. H., Ostwald, M.J., \& Williams, A. (2011). Teaching creative design: A challenging field. In Proceedings of the DESIRE'11 Conference on Creativity and Innovation in Design.

Bartlett Book 2016. Retrieved from: https://issuu.com/ bartlettarchucl/docs/bartlettbook 2016.

Benjamin, A. (2000)

Architectural philosophy. London, UK: Athlone Press/Bloomsbury.

Buck-Morss, S. (1991). The dialectics of seeing: Walter Benjamin and the Arcades Project. Cambridge, MA: The MIT Press.

Collins, P. (1966). Architectural criteria \& French traditions. Journal of Architectural Education (1947-1974), Vol. 21, pp. 67-71.

Costi, D. (2014). Tubascular. Retrieved from http:// superarchitects.world/portfolio/ tubascular/

Day, G. (2012). Manfredo Tafuri, Fredric Jameson and the contestations of political memory. Historical Materialism, 20.1, pp. 31-77.

Dickens, D. (2015). Drop dead city. Retrieved from http:// superarchitects.world/portfolio/ drop-dead-city/

Doležel, L. (2000).

Heterocosmica: Fiction and possible worlds. Baltimore, MD: John Hopkins University Press.

Fleming, D. J. (2003). The very idea of a Progymnasmata.

Rhetoric Review, Vol.22, No.2, pp. 105-122.

Frichot, H. (2009). On the death of architectural theory and other spectres. Design Principles and Practices, Vol. 3, pp.113-122.

Gandy, M. (2010). The persistence of complexity: Re-reading Donna Haraway's Cyborg Manifesto. AA Files, No. 60, pp. 42-44.

Gilloch, G. (2013). Walter Benjamin and the city. Hoboken, $\mathrm{NJ}$ : Wiley Press.

Harman, G. (2002). Tool-being: Heidegger and the metaphysics of objects. Chicago, IL: Open Court.

Heidegger, M. (1977). The question concerning technology, and other essays (W. Lovitt, Trans.). New York, NY: Garland Press.

Hirst, P. (1993). Foucault and architecture. AA Files, No. 26, pp. 52-60.

Hühn, P., Meister J-C., Pier, J., Scmid, J. (Eds.) (2016). Narrativity. In The living handbook of narratology. Retrieved from http:// www.lhn.uni-hamburg.de/

Jameson, F. (2005)

Archaeologies of the future: The desire called utopia and other science fictions. London, UK: Verso Press.

Jarosinski, E. (2009). Of stones and glass houses: Minima moralia as critique of transparency. In G. Richter (Ed.), Language without soil: Adorno and late philosophical modernity. New York, NY: Fordham University Press.

Kripke, S. (1972). Naming and necessity. Cambridge, UK: Cambridge University Press.

Lewis, D. (1973). Counterfactuals. Cambridge, MA: Harvard University Press.

Nicholson, B. (1990). Appliance

house. Chicago Institute for Architecture and Urbanism.

Ostwald, M.J. \& Williams, A. (2008). Understanding architectura/ education in Australasia, Volume 2: Results and recommendations. Australian Learning and Teaching Council, June 2008.

Pawley, M. \& Tschumi, B. (1971). The Beaux Arts since 1968. Architectural Design, 41, pp. 533-566.

Qin, S. (2014). Paradise of paradises. Retrieved from http:// cargocollective.com/sunnyqin/ Paradise-of-Paradises
Qin, S. (2014). City of Mainkon. Retrieved from http:// cargocollective.com/sunnyqin/ City-of-Mainkon

Spuybroek, L. (2004). NOX: Machining architecture. London, UK: Thames and Hudson.

Tafuri, M. (1976). Architecture and utopia: Design and capitalist development, (B. Luigia La Penta Trans.). Cambridge, MA: The MIT Press.

Tafuri, M. (1987). The sphere and the labyrinth: Avant-Gardes and architecture from Piranesi to the 1970s (P. d'Acierno, R. Connolly, Trans.). Cambridge, MA: The MIT Press.

Weismehl, L. A. (1967). Changes in French architectural education. Journal of Architectural Education, Vol. 21, No. 3, pp. 1-3. 